\title{
PERCEIVED QUALITY OF HEALTHCARE DELIVERY IN A RURAL DISTRICT OF GHANA
}

\author{
P. K. TURKSON \\ University of Cape Coast, University Post Office, Cape Coast, Ghana
}

Author for correspondence: Professor Paa Kobina Turkson

Conflict of interest: None declared

\section{SUMMARY}

Objective: The study aimed at finding out clients' perceptions of the quality of healthcare delivery at the district level in rural Ghana, using the Komenda-EdinaEguafo-Abrem District as a case study.

Design: 803 patients were purposively selected and interviewed after visits to health facilities using a pretested questionnaire, while focus group discussions were held in 13 communities. The study was done between October 2003 and August 2004.

Results: The majority of respondents $(70 \%)$ were females. The mean expected maximum waiting time for seeking medical help was $1 \mathrm{hr}$. About $98 \%$ said they were asked to explain their problem. However, lower proportions, $74 \%, 43 \%$ and $46 \%$ were physically examined, told what was wrong, or given advice about their illness, respectively. About $90 \%$ of the respondents were satisfied or very satisfied with the care given during their visit to the health facility. The participants perceived poor attitude of some health workers, long waiting times, high cost of services, inadequate staff, policy of payment for health services, frequent referrals to hospitals, and lack of ambulances at facilities as being detrimental to effective delivery of quality healthcare.

Conclusions: The study found that generally the quality of healthcare delivery was perceived to be high for most of the indicators used. There were, however, some concerns that patients were not told the diagnosis or informed about the management of their illness. These need to be addressed. The level of satisfaction with quality of healthcare was high.

Keywords: Perception, Primary healthcare, Quality care, Ghana, Patient satisfaction, Healthcare delivery.

\section{INTRODUCTION}

The Ministry of Health $(\mathrm{MOH})$ in Ghana has been concerned about quality of care, but improvements in quality have been slow partly because quality improvement activities have received inadequate priority. ${ }^{1}$ There have been efforts to research into quality of healthcare and institutionalisation of quality assurance in Ghanaian health facilities. These were initiated through a project from 1993-1996 and then 1998-1999 in the
Email: kobbiecc@yahoo.com

Upper West Region and some facilities in Eastern and Volta Regions. ${ }^{2,3}$ There continue to be complaints about the quality of care given by health workers or received by clients.

Poor quality of healthcare results in loss of customers, lives, revenue, material resources, time, morale, staff, recognition, trust and respect ${ }^{4}$ and in individual and communities' apathy towards health services, all of which contribute to lowered effectiveness and efficiency. The $\mathrm{MOH}$ has identified improving the quality of healthcare as one its five key objectives of health sector reforms in Ghana. It envisages that quality of care might be improved through paying more attention to the perspectives of clients, improving the competencies and skills of providers and improving working environment by better management, provision of medical equipment and supplies and motivation of staff. ${ }^{\mathbf{5}}$

It has been suggested that if health programmes are to succeed in resource-poor countries, it is important to get the opinions of the local people in addition to their degree of satisfaction with available services. ${ }^{6}$ The patient's perception of quality of care is critical to understanding the relationship between quality of care and utilisation of health services and is now considered an outcome of healthcare delivery. ${ }^{7,8}$

The objective of the study was to identify patient, community, staff and operational problems constraining the effectiveness and efficiency of healthcare delivery at the district level. An assessment of the performance of the health sector at the district level from the clients' perspective would likely reveal certain constraints to provision of quality care and would provide an opportunity for the prioritisation and institutionalisation of a quality assurance programme to help the health sector achieve its goal of better health and healthcare for rural dwellers.

The study explored the perceptions of patients regarding quality of healthcare received, so as to identify areas for possible intervention to help improve patient satisfaction with healthcare delivery in the district. 
Understanding the determinants of client satisfaction will help policy and decision-makers to plan and implement programmes that meet the needs of patients as perceived by users of health services.

\section{METHODS}

The study area was chosen primarily because it is typically rural with over $70 \%$ of the population in the rural areas. The Komenda-Edina-Eguafo-Abrem (KEEA) District is found in the Central Region of Ghana. It covers 391 square kilometres and is bordered on the northeast by Twifo-Heman Lower Denkyira District. To the northwest is Mpoho Wassa District in the Western Region, to the east is Cape Coast District and to the west is Shama-Ahanta East District in the Western Region. The southern border is made up by the sea (the Gulf of Guinea). It has 5 traditional councils, namely Edina, Komenda, Eguafo, Abrem and Agona with a total population of about 118,000 as at 2002 .

The district has 1 specialist hospital for skin problems, 4 health centres/post/clinics, 1 private medical practitioner, 2 private maternity homes and 1 community clinic. Health services are provided at two levels. Level A services are provided by community health workers trained as health educators. These assist Ghana Health Service workers in educating communities on health promotion and disease control/surveillance. Community health officers are involved in community-based health planning and services in 3 zones. The level B services are provided at health centres and posts where minor ailments are treated. Programmes carried out at level B include immunization, health education, counselling including family planning, disease control, antenatal and postnatal care services, and supervision of level A workers. There is no level C facility so complicated cases are referred outside the district.

\section{Data collection, processing and analyses}

The methods used were exit interviews in all the health facilities and focus group discussions (FGDs) in some communities. A total of 803 patients (made up as follows: Komenda Health Centre, 107; Elmina Health Centre 240; Agona Health Centre, 99; Ankaful Hospital, 99; Kissi Health Centre, 258) were interviewed immediately after contact with health services/facility in November-December 2003 in the health facility. Consecutive patients were approached after leaving the dispensary and asked for consent to be interviewed with assurance of no retribution for non-participation. Those unwilling to participate were excluded.

Information on satisfaction or dissatisfaction with the services received, and perceptions and experiences of healthcare delivery were solicited using a questionnaire.
Prior to the questionnaire administration, 10 data collectors were trained to understand the questionnaire, role play as interviewer and interviewee, agree on a common translation of questions into the local language (Fanti) and pre-test the questionnaire on 10 patients at the Elmina Health Centre. The questionnaire had 32 questions (with 23 closed) and took about 20 minutes on average to administer. The questions covered socio-demographic issues, waiting time and interactions with service providers. Others were on assessment of cleanliness of the facility, satisfaction with visit and availability of prescribed drugs. Procedures at the health facilities were also observed surreptitiously to crosscheck clients' perception of attitudes and waiting times.

Focus Group Discussions (FGDs) were held in 13 communities chosen randomly out of 158 communities in June and July 2004. The names of the 13 communities were picked from a box with the names of all the 158 communities. The FGDs provided information on the community's perceptions of issues related to health problems, healthcare and service performance and supported some of the findings from the exit interviews. The participants were community members chosen by health volunteers in the various communities based mainly on gender balance, use of health services and availability of the participant. The number of participants ranged from 8-12 in a community. Proceedings of the discussions were taped after permission was sought from the participants.

\section{Data analysis}

Data entry and analyses involving mainly frequencies, percentages, means and standard deviations were done using Statistical Package for Social Sciences (SPSS) version 11.0.0 for windows (SPSS Inc., Chicago, IL, USA). for the exit interviews. For the FGDs, the taped proceedings were transcribed and compared with recorder's notes taken during the discussions to ensure reasonable accuracy of transcriptions. For the questions dealing with satisfaction, only the percentages in the "very satisfied" class (top box) were used for comparison. This is known as the "top-box method" and is used to increase sensitivity in scored scale items.'

\section{Sources of bias/limitations}

As with most rapid appraisal methods, a major source of bias was using purposive or convenience sampling so that extrapolations to other populations might not be entirely appropriate. The use of interviews, FGDs and observations was aimed at crosschecking findings from each source. Translating some questions or words from English to Fanti was difficult. 
This resulted sometimes in the interviewer posing leading questions or probing much more. To reduce these, a common translation was adopted for the data collectors to use.

The major ethical issue encountered was confidentiality of the patients and also of the health centres. This was ensured by leaving out patient identities from the questionnaires and aggregating the results at the district level. Similarly, participants in the FGDs were encouraged not to use names or identifiable titles in addressing others during the recording of the proceedings. Informed consent was sought verbally before each interview or FGD.

\section{RESULTS}

\section{Clinic exit interviews}

Females dominated representing $70.2 \%(n=803)$ of the respondents. The mean age ( \pm standard deviation) was $32 \pm 12$ years. The respondents were almost equally divided into those who were patients i.e. they were at the clinic for their own healthcare needs $(50.7 \%)$ and those who had accompanied patients (children, spouses and other family members) (49.3\%).

The majority $(83.3 \%)$ said they waited for less than 1 $\mathrm{hr}$ before being registered or receiving their card. Those waiting for one to two hours and more than two hours were $14.7 \%$ and $1.9 \%$, respectively. The majority (83.4\%) found the waiting time reasonable. The proportion of respondents who waited for less than one hour between receiving their card and seeing the medical assistant was $52.2 \%$, with the rest waiting for more than 1 hour. The mean waiting time reported by the respondents between receiving their card and seeing the medical assistant was $50 \pm 32 \mathrm{~min}$. The mean $( \pm$ SD) of the total waiting time from arrival at the clinic to seeing a medical assistant anticipated by respondents was $49 \pm 32 \min (n=683)$. Table 1 presents the findings of this study using some indicators.

Table 2 gives the proportions of respondents assessing categories of attitude of the various health workers in the facilities. The proportions of respondents and their rating of cleanliness in the various facilities and their surroundings were as follows: very clean $23.3 \%$; clean $56.8 \%$; fairly clean $17.3 \%$; dirty $1.4 \%$; very dirty $0.2 \%$ and no response $1.0 \%$.

Table 1 Indicators of quality care: Proportions of respondents in KEEA District, Ghana who said "Yes"

\begin{tabular}{ll}
\hline Indicator & $\begin{array}{l}\text { \% } \\
(\mathbf{n = 8 0 3})\end{array}$ \\
$\begin{array}{l}\text { They were asked by doctor to explain } \\
\text { problem }\end{array}$ & 97.9 \\
$\begin{array}{l}\text { They were physically examined } \\
\text { They were told what was wrong }\end{array}$ & 73.8 \\
$\begin{array}{l}\text { They were given instruction /advice about } \\
\text { illness }\end{array}$ & 43.3 \\
$\begin{array}{l}\text { Other people were in consulting room (No } \\
\text { privacy) }\end{array}$ & 10.5 \\
$\begin{array}{l}\text { They received all prescribed drugs } \\
\begin{array}{l}\text { Instructions given by dispensary staff were } \\
\text { clear }\end{array}\end{array}$ & 83.4 \\
\hline
\end{tabular}

The levels of satisfaction and the proportions of respondents were as follows: very satisfied, $26.5 \%$; satisfied, $62.8 \%$; fairly satisfied, $6.4 \%$; dissatisfied, $1.4 \%$; very dissatisfied, $0.2 \%$ and no response, $2.7 \%$. A proxy used for satisfaction with care given in the facility was whether or not a respondent was willing to recommend a facility to a friend or to go back to a facility. About $94 \%$ of the respondents were willing to recommend the facility to a friend or to go back to the facility.

Table 2 Attitudes of health workers as perceived by respondents $(n=803)$

\begin{tabular}{lcccc}
\hline & $\begin{array}{c}\text { Record } \\
\text { keepers }\end{array}$ & $\begin{array}{c}\text { OPD } \\
\text { Nurses }\end{array}$ & $\begin{array}{c}\text { Medical } \\
\text { Assistant }\end{array}$ & $\begin{array}{c}\text { Dispen- } \\
\text { sary staff }\end{array}$ \\
Very good $(\%)$ & 38.0 & 27.1 & 47.9 & 38.9 \\
Good $(\%)$ & 57.0 & 36.7 & 47.2 & 52.2 \\
Fairly good $(\%)$ & 3.0 & 1.9 & 2.4 & 5.1 \\
Poor $(\%)$ & 0.6 & 0.4 & 0.7 & 1.2 \\
Very poor & 0 & 0.1 & 0 & 0.1 \\
No response $(\%)$ & 1.4 & 0 & 1.7 & 2.5 \\
No nurse available $(\%)$ & - & 33.7 & - & - \\
\hline
\end{tabular}

\section{Community Focus Group Discussions}

The majority of discussants said that the quality of services in most of the facilities was acceptable. However, they identified specific issues with potential to impact- ing utilisation and quality of care to include the following:

- The range of drugs given was limited to mainly painkillers, vitamins and antimalarials. A partici- 
pant said "Paracetamol, vitamin B complex and nivaquine are often given"

- The staff were inadequate so the few available were overworked and tired affecting their performance.

- The referrals were too many and costly, encouraging self-medication. They suggested having qualified medical doctors visit on specified days to reduce referrals.

- There was the need to provide ambulances or vehicles especially to help transport referred cases. A participant said: "If we go with a taxi, we have to let the taxi wait to know if we would be referred. Otherwise if we let the taxi go, we end up having problems getting a vehicle to send the referral to the hospital."

- Some health workers were perceived as rude, unfriendly, unapproachable or impatient, or did not respect patients.

- Favouritism was sometimes practiced to the chagrin of other patients. They advocated respect for all.

- There were no services on weekends, with only emergencies being treated. In certain facilities medical assistants were not available over the weekends.

- Waiting times were longer, especially at the dispensary or when going for an injection. The suggested ideal total waiting time for seeking medical help was one hour.

- There was the need to provide an Information or Complaints desk to help clients.

- Health workers should be effectively supervised to reduce illegal charges.

\section{DISCUSSION}

The study found out that the majority of respondents were satisfied or very satisfied with the quality of healthcare delivery in the district in the exit interviews. Most of the indicators of quality used were scored positive by higher proportions of respondents. However, during the FGDs participants perceived poor attitude of some health workers, long waiting times, high cost of services, inadequate staff, policy of payment for health services, frequent referrals to hospitals, and lack of ambulances at facilities as being detrimental to effective delivery of quality healthcare.

The majority of respondents in the clinic exit interviews were females. Females might play important roles in healthcare because if they were not patients themselves, they were most likely to accompany other patients, especially children or husbands. Men, reportedly, are more likely to be at a clinic for their own healthcare needs. ${ }^{6}$
Among the factors suggested to influence how patients experience a service are responsiveness and empathy. ${ }^{10}$ These might be outwardly displayed in the attitude of health workers. Generally, the respondents in our study perceived the attitude of the various categories of health workers to be good or very good (Table 2 ). Mothers attending child welfare clinic in the same district had perceived the attitude of service providers to be good because they were well received and attended to. ${ }^{\mathbf{1 1}}$

The most powerful predictor for client satisfaction with services in rural Bangladesh was provider attitude or behaviour, especially showing respect and politeness for patients. ${ }^{12}$ This was more important than technical competence of the provider. Some health workers were perceived to have poor attitude. Improving the attitude of health personnel towards patients is said to enhance perceived quality of care. ${ }^{\mathbf{1 3}}$ Good interpersonal relation establishes trust and credibility by demonstrating respect, confidentiality, courtesy, responsiveness and empathy. $^{14}$

Generally, the clients in our study found the cleanliness of the facilities to be good or very good. Basic amenities of health services such as clean waiting rooms are aspects often highly valued by patients. ${ }^{15}$ Efforts would have to be made to maintain this.

Prompt attention has been shown to be a key dimension in surveys of community satisfaction with health services. ${ }^{16,}$ 17, 18, 19, 20 Individuals value prompt attention because it might lead to better health outcomes, allaying fears and concerns that come with waiting for diagnosis and treatment. ${ }^{21}$ Prompt attention on its own is not a function of health improvement, but it is a dimension of patient satisfaction. ${ }^{19}$ In our study, the ideal total waiting time was about $1 \mathrm{hr}$ and patients expected to be seen quickly, attributing long waiting times to unnecessary delays. Some patients identified the dispensary and injection rooms as places likely to delay patients, so management will have to find out the causes of such delay and help minimize these. Longer waiting times were found to be significantly associated with lower satisfaction scores among patients in Mozambique. ${ }^{6}$

The proportion of respondents who said they were asked by the doctor to explain their problem has been used as an indicator in assessing quality of healthcare. ${ }^{4}$ In our study this was very high (Table 1) and is commendable. Another indicator is the proportion that said they were physically examined, which was fairly high. However, some respondents said that physical examinations were either not done at all or done in a perfunctory manner, lacking thoroughness. 
Some said that sometimes prescriptions were written even before examinations were done which was discouraging. These ought to be further investigated.

A further indicator of quality was proportion of respondents who were told the diagnosis. This was low (Table 1). The Ghana Health Service Patient's Charter states that the patient has the right to full information on his or her condition and management and the possible risks involved. The District Health Management Team will have to educate health workers about this right and encourage information to be shared in a responsible manner.

We used the proportion of respondents who were given instructions or advice about their illness as part of the consultation also as an indicator. We found this to be low (46\%). Again, the Patient's Charter enjoins health staff to inform or educate patients about their illnesses. Communication between health workers and patients is a key component of patient satisfaction. ${ }^{22}$ Good communication and caring relationship are important in achieving patient satisfaction. ${ }^{\mathbf{2 3}}$

There was a high level of privacy in the consulting rooms (Table 1). However, initial screening of patients at the Out Patients' Department (OPD) was done in the open. Providing cubicles or screens will assure patients of confidentiality. Patients are more likely to give important medical history information to healthcare providers if there is respect for confidentiality. ${ }^{21}$ In rural Bangladesh, the second most powerful predictor for patient satisfaction with service delivery was the respect for privacy. ${ }^{12}$

We found that the proportion of 20 most prescribed drugs in the 4 health centres in the district that were on the list of tracer drugs approved by the Ghana Health Services ranged from $62-76 \%$. This could explain why some drugs were not available. A number of studies suggest that appropriate drug policies are among the most important policy actions likely to improve quality of healthcare as drug supply is a very important determinant of utilisation of health services. ${ }^{13,24,25,26}$

Patient satisfaction is generally considered as the extent to which the patient feels his needs and expectations are met by the services provided ${ }^{27}$ and predicts both compliances $^{28}$ and utilisation. ${ }^{29}$ As high as $89 \%$ of the respondents in our study were satisfied or very satisfied with their visit to a health facility. However, less than a third was in the very satisfied category (the top box). Efforts should be made to increase the "very satisfied" proportion in this district.
What clients expect of services is instructive in making services responsive to the needs of patients and the community, and is also used in assessing quality of healthcare delivery. The expectations of respondents in our study from the FGD included nice reception from health workers; drugs being available and affordable in the dispensary, so that they could receive all their prescriptions at one place; being well or thoroughly examined by the doctor, which gives the patient the confidence that the doctor is knowledgeable and cares and will go to great lengths to get the correct diagnosis; and receiving good and prompt medical attention. The perceptions of rural Mozambicans of healthcare services were similar ${ }^{6}$ pointing to a possible common challenge in healthcare delivery in rural settings in developing countries.

Some policy issues requiring action by DHMT were identified. One policy action is to institute regular customer-relations training courses run professionally to help staff improve or maintain good inter-personal skills. Furthermore, the Patient's Charter and Rights should be enforced vigorously after educating all health workers on these. Complaint desks should be established at all facilities with assurance that concerns would be addressed effectively, while allaying fears of victimization. Screens or cubicles should be provided at the outpatient department to improve privacy. Lastly, the national drugs policies and essential drugs list need to be reviewed, making them more responsive to patients' needs and improving availability.

The study concluded that the quality of healthcare as measured by the indicators used were generally perceived to be high except in patients not being told the diagnosis or given instructions or advise about their illness. There were concerns about the attitude of some staff and unavailability of some drugs. These should be addressed to improve quality further. Overall, the level of satisfaction was high and is commendable.

\section{ACKNOWLEDGEMENTS}

This paper is part of a study carried out with financial assistance from the Ghanaian Dutch Collaboration for Health Research and Development under contract number 2002/56/GD. We are sincerely grateful for the support. The contributions of Dr S T Kwashie, Dr K Ekumah and the late Dr P Abu as collaborators are hereby acknowledged. Dr Y Ofori Yeboah, Ms Lorinda Tetteh and Ms Admire Owusu of the District Health Management Team, Elmina are specially commended for their technical support. We are indebted to the data collectors Ms Judith Haizel, Messrs Victor Amoah, Justice Annan, Eric Entsie, Anthony Nyame, Joseph Boppey, Paul Bofoh and Eric Owusu-Asare and Ms Edna Dogoe for their help. 


\section{REFERENCES}

1. Doyle V and Haran D. Quality Assurance in healthcare. Policy Briefings for Health Sector Reform. Health Sector Reform Research Work Programme (Liverpool School of Tropical Medicine). 2000 Paper number 1.

2. Liverpool School of Tropical Medicine. Quality assurance in Ghana. Research Project PN2. Health Sector Reform Research Work Programme. Undated. Available at:

http://www.liv.ac.uk/lstm/hsr/hsrpn2.html. Accessed on 25 August 2004.

3. Haran D, Dovlo D and Offei A. The quality of care in hospitals and health centres in Eastern Region: a view from the patients. Ghana. Eastern Region. Ministry of Health 1994. Unpublished research report.

4. Bannerman C, Offei A, Acquah S D and Tweneboa N A. Health Care Quality Assurance Manual, Ghana Health Services, 2002. 84p.

5. Ministry of Health, Ghana. The second health sector 5 year programme of work 2002-2006. Partnerships for health: Bridging the inequalities gap. MOH/PD/005/03/02/GD 2002

6. Newman R D, Gloyd S, Nyangezi J M, Machabo F and Muiser J. Satisfaction with outpatient healthcare services in Manica Provinca, Mozambique. Health Policy Plan 1998; 13: 174-180.

7. Ross C K, Steward C A, Sinacore J M. The importance of patient preferences in the measurement of healthcare satisfaction. Med Care 1993; 25: 113849.

8. Reerink I and Sauerborn R. Quality of care in primary care setting in developing countries. Recent experiences and future directions. Int $J$ Qual Healthcare 1996; 8: 131-139

9. Dunn E F and Carmhiel J B. Patient satisfaction studies: what do the results really mean? J Outcomes Manag 1996; 3: 10-14.

10. Smith $\mathrm{M}$ and Engelbrecht B. Guide to assessing client satisfaction at district hospitals. National Department of Health and the Health Systems Trust, South Africa. 2001

11. Bosu W K, Ahelegbe D, Edum-Fotwe E, Bainson $\mathrm{K} \mathrm{A}$, and Turkson $\mathrm{P} \mathrm{K}$. Factors influencing attendance to immunization sessions for children in rural district of Ghana. Acta Trop 1997; 68: 259-267

12. Aldana J M, Piechulek $\mathrm{H}$ and Al-sabir A. Client satisfaction and quality of healthcare in rural Bangladesh. Bull World Health Organ 2001; 79: 512-517

13. Balthussen R M, Ye Y, Haddad S and Sauerborn R S. Perceived quality of care of primary healthcare services in Burkina Faso. Health Policy Plan 2002; 17: 42-48
14. Brown L D, Franco L M, Rafeh N and Hatzell T. Quality assurance of healthcare in developing countries. Quality Assurance Methodology Refinement Series. Quality Assurance Project, USA 1993 33p.

15. Bernhart M H, Wiadnyana I G P, Wihardjo $\mathrm{H}$ and Pohan I. Patient satisfaction in developing countries. Soc Sci Med 1999; 48: 989-996

16. Carr-Hill R A. The measurement of patient satisfaction. J Public Health Med 1992; 14: 236-249.

17. Ross C K, Steward C A, and Sinacore J M. A comparative study of seven measures of patient satisfaction. Med Care 1995; 33: 392-406.

18. Thompson A G and Sunol R. Expectations as determinants of patients' satisfaction: Concepts, theory and evidence. Int J Qual Health Care 1995; 7: 127-141

19. Cohen G, Forbes J, and Garraway M. Can different patient satisfaction survey methods yield consistent results? Comparison of three surveys. $\mathrm{Br}$ Med J 1996; 313: 841-4.

20. Sitzia J, Wood N. Patient satisfaction: a review of issues and concepts. Soc Sci Med 1997; 45: 18291843

21. Murray C J and Frenk J. A framework for assessing the performance of health systems. Bull World Health Organ 2000; 78: 717-731

22. Nelson A M, Wood S, Brown S, Bronkesh S and Gerbarg E. Improving patient satisfaction now: How to earn patient and payer loyalty. Aspen. Gaithersburg MD. 1997

23. Fitzpatrick R. Survey of patient satisfaction I: Important general consideration. Br Med J 1991; 302: 887-889

24. Waddington $\mathrm{C} \mathrm{J}$ and Enyimayew $\mathrm{K}$ A. A price to pay: the impact of user charges in Ashanti-Akyin District, Ghana. Int J Health Plann Manage 1989; 4: $17-47$

25. Waddington $\mathrm{C} \mathbf{J}$ and Enyimayew $\mathrm{K}$ A. A price to pay: the impact of user charges in the Volta Region, Ghana. Int J Health Plann Manage 1990; 5: 287-312.

26. Haddad S and Fournier P. Quality, costs and utilization of health services in developing countries. A longitudinal study in Zaire. Soc Sci Med 1995; 40: 743-753

27. Al-Daghaither A H and Saeed A A. Consumers' satisfaction with primary health services in the city of Jeddah, Saudi Arabia. Saudi Med J. 2000; 21: 447-54

28. Kincey J, Bradshaw P and Ley P. Patients' satisfaction and reported acceptance of advice in general practice. Gen Pract 1975; 25: 558-566

29. Roghmann K, Hengst A, and Zastowny T. Satisfaction with medical care: its measurement and relation to utilization. Med Care 1979; 17: 461-4 